\title{
THE EFFECT OF HYPOTHERMIA AND OTHER FACTORS ON CEREBROSPINAL FLUID PRESSURE ${ }^{1}$
}

Jack Posnikoff, m.D., Joseph Stratford, M.d., and William Feindel, M.D. ${ }^{2}$

HAEMODYNAMIC FACTORS have long been stressed as important in the maintenance of cerebrospinal fluid pressure. Percival Bailey stated that it was influenced by both arterial and venous pressure (1). The precise relationships, however, remain a matter of controversy and this applies, in particular, to the consideration of hypothermia.

The experimental reduction of cerebrospinal fluid pressure (2) and the clinicall observation of a "slack" brain at operation with hypothermia has been well documented $(3,4)$. The extremely close relationship between cerebrospinal fluid pressure and venous pressure reduction during hypothermia was previously emphasized (2), but in our experiments this only occurred under specific circumstances. Both in normothermia and hypothermia the relationship of haemodynamic changes to cerebrospinal fluid pressure proved complex. Multiple simultaneous recordings demonstrated this complexity.

\section{METHOD}

Utilizing intravenous Nembutal ${ }^{\circledR}$, the initial dose being $30 \mathrm{mg} . / \mathrm{kg} ., 33 \mathrm{dogs}$ were surface cooled. Ten dogs were subsequently excluded from this series because they received other pharmacological agents, some of which produce direct haemodynamic changes (5). Eight additional dogs were subjected to repeated normothermic procedures mentioned below.

Temperature readings were obtained with a paracardiac intra-oesophageal thermistor. Pulse rate and aortic blood pressure were recorded by means of intravascular cannulation of the femoral artery rather than the carotid artery. This lessened the possibility of disturbing intracranial circulation (6). Venous pressure was recorded from the inferior vena cava via the femoral vein, jugular pressure being obtained only in certain experiments. This also lessened the possibility of disturbing cerebral circulation. Respiration was reflected in both venous and cerebrospinal fluid fuctuations. Either electromyography or electrocardiography was employed as supplementary measures for the detection of shivering or straining.

Cerebrospinal fluid pressure was recorded by means of a polyethylene catheter

'From the Neurosurgical Research Laboratory, Department of Surgery (Neurosurgery), Cniversity of Saskatchewan, Saskatoon. Presented in part as "Cerebrospinal Fluid Pressure "n Hypothermia," Fourteenth Annual Scientific Meeting, Western Regional Group, Division of Medical Research, National Research Council of Canada, January 25, 1960.

This work was aided by a research grant from the National Research Council of Canada.

${ }^{2}$ Present address: Montreal Neurological Institute, Montreal, P.Q.

Can. Anaes. Soc. J., vol. 7. no. 4, October, 1960 
threaded caudally through the cisterna magna via a No. 15 needle. A wide bore catheter was used in order to show minor fluctuations (7). A 2-hour period of observation prior to hypothermia was essential to ensure that cerebrospinal fluid pressure was not falling because of leakage about the catheter.

Endotracheal intubation with pressure cuff was used in all dogs. For reasons to be discussed later, spontaneous respiration, supplemented by positive-pressure respiration when necessary, was the respiratory method of choice.

Temperature was usually not carried below $25^{\circ} \mathrm{C}$. in the hypothermia experiments. The rewarming phase, which is not mentioned in many articles on hypothermia, was recorded in this series.

Quantitatively measurable values (respiration, pulse rate and arterial, venous, and cerebrospinal fluid pressures) were simultaneously recorded with a Grass polygraphic recording unit. The quantitative changes were then graphically illustrated as percentage changes of the initial values in order to compare our results with those of others (2). Examples have been selected for illustration and discussion.

\section{Hypothermia}

\section{RESLLTS}

The method of subarachnoid catheterization described proved to be a more benign and reliable procedure than that of metal needle placements and, in most

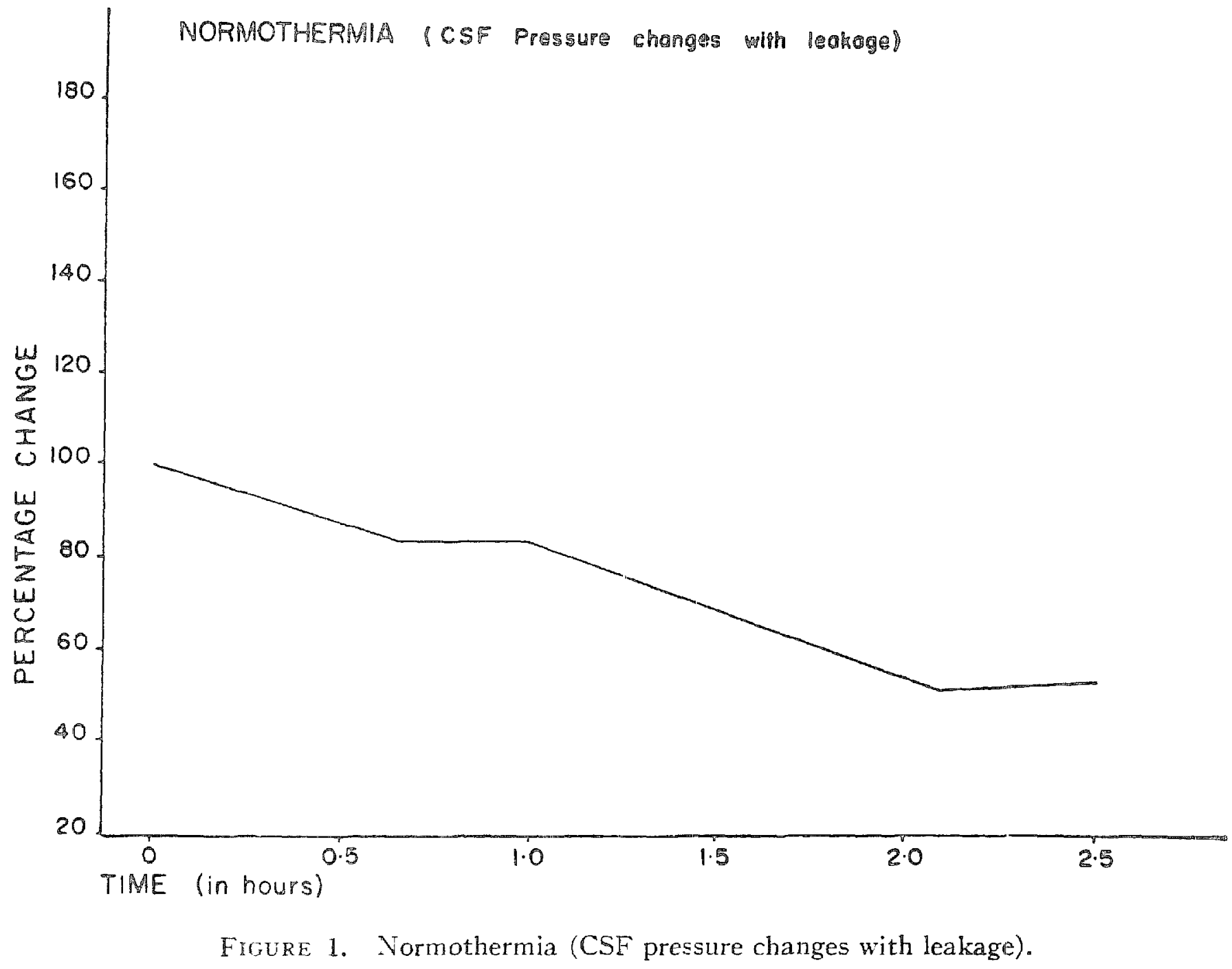


cases, cerebrospinal fluid leakage was avoided. An example with leakage, however, illustrates the necessity of the preliminary waiting period before proceeding with hypothermia (Fig. 1).

Using a previously described method of mechanical positive-negative respiration (2), we could not obtain completely satisfactory cerebrospinal fluid pressure reductions. The most satisfactory method finally evolved was one of spontaneous respiration supplemented, when necessary, by positive-pressure respiration at a rate previously found to maintain adequate oxygenation and fairly constant $\mathrm{pH}$ and $\mathrm{pCO}_{2}$ at any given temperature (8).

Under "basal" conditions of hypothermia, that is, with adequate respiration and absence of straining or shivering, the results obtained tended to follow certain general trends which were graphically distinctive. Figure 2 is an example chosen to illustrate some of these features. In practically every experiment, arterial, venous, and cerebrospinal fluid pressure showed some transient initial increase with cooling and this occurred even when extremely làrge doses of Nembutal ${ }^{(}$ were used. Subsequently, arterial pressure declined progressively. Venous pressure reduction, however, was generally less uniform but tended to approximate the arterial pressure reduction when the lower temperature ranges were reached. The final cerebrospinal fluid pressure reduction was greater than either the venous or the arterial pressure reductions. The pulse rate, following a short initial delay coincident with the rise of the above values, declined in a most constant and

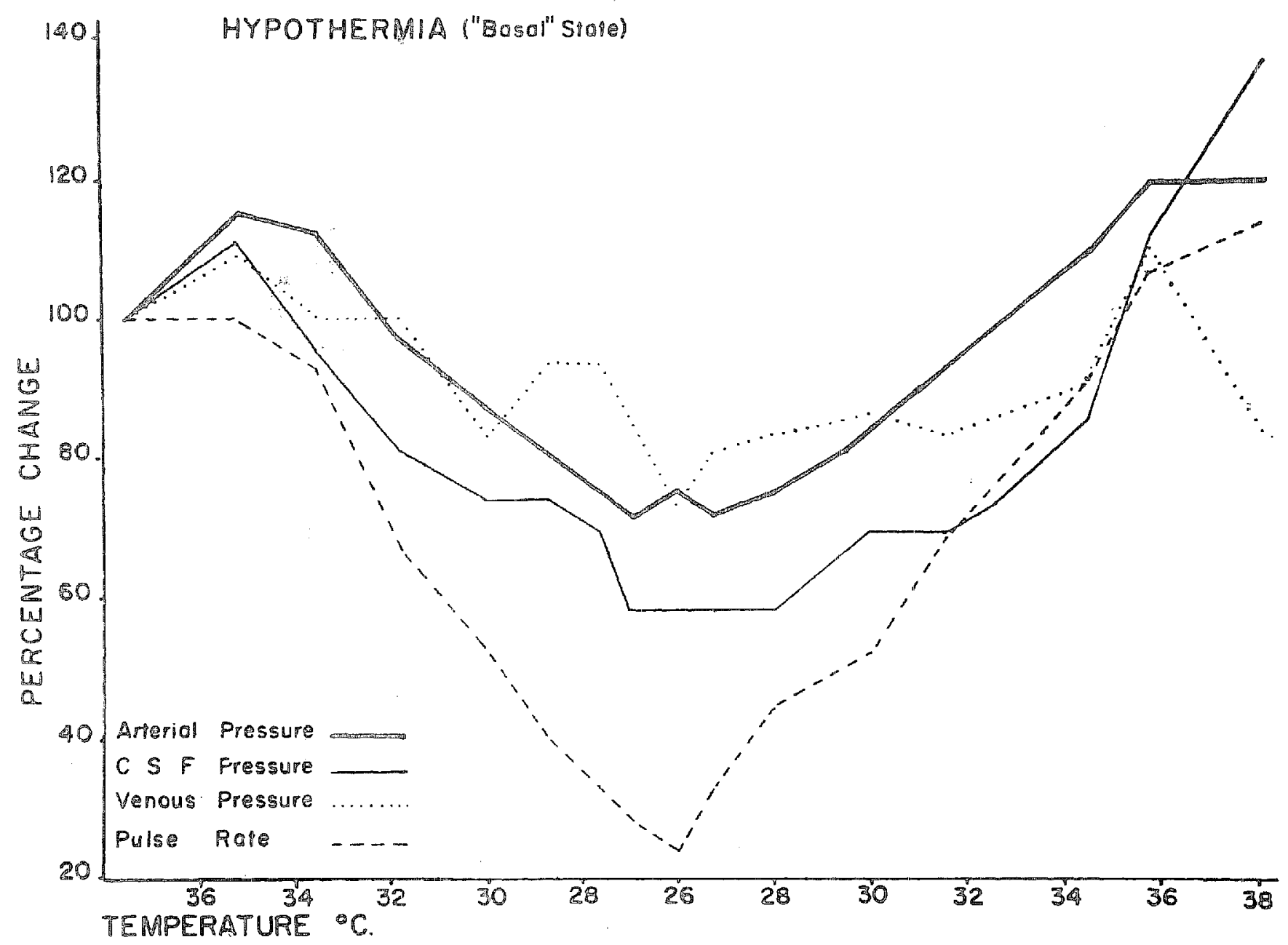

Figure 2. Hypothermia ("basal" state). 
progressive manner. This feature of pulse rate change during cooling is comparable to the rate of decline previously recorded by other investigators $(9,10)$. An actual initial increase of pulse rate with cooling was not observed. Deviations from this pulse rate pattern occurred during circumstances associated with an inadequate "basal" state.

Figure 3 illustrates a recording that was dbtained in the initial experiments, prior to the development of a reliable method of producing a "basal" state. With inadequate respiratory function there was a moderate increase of cerebrospinal fluid pressure, a marked increase of venous pressure and a slight increase in pulse rate. Cerebrospinal fluid and venous pressures were reduced by instituting assisted respiration.

Figure 4 is an example of the recordings pbtained with mechanical positivenegative respiration. With this method of respiration there was only a moderate reduction of pulse rate, venous pressure, arterial pressure, and cerebrospinal fluid pressure.

Figure 5 illustrates another aspect of earlier experiments with inadequate respiratory assistance during cooling. The result was a minimal reduction in arterial, venous, and cerebrospinal fluid pressures and an inconstant pulse rate reduction. The onset of assisted respiration coincided with a definite decrease in venous and cerebrospinal fluid pressures. With inadequate respiration there usually was a fairly close relationship between venous and cerebrospinal fluid pressures.

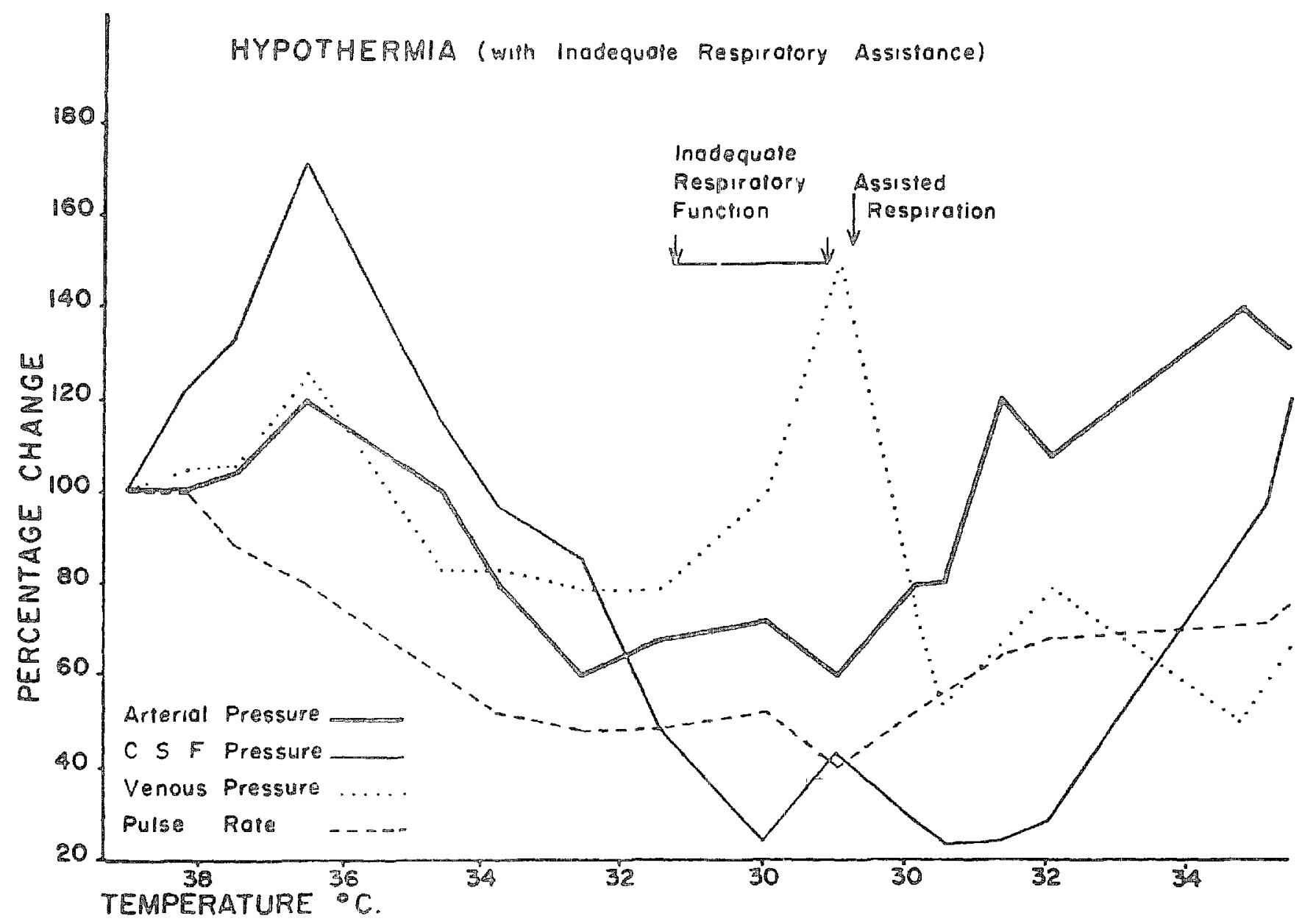

FigURE 3. Hypothermia (inadequate respiratory assistance). 

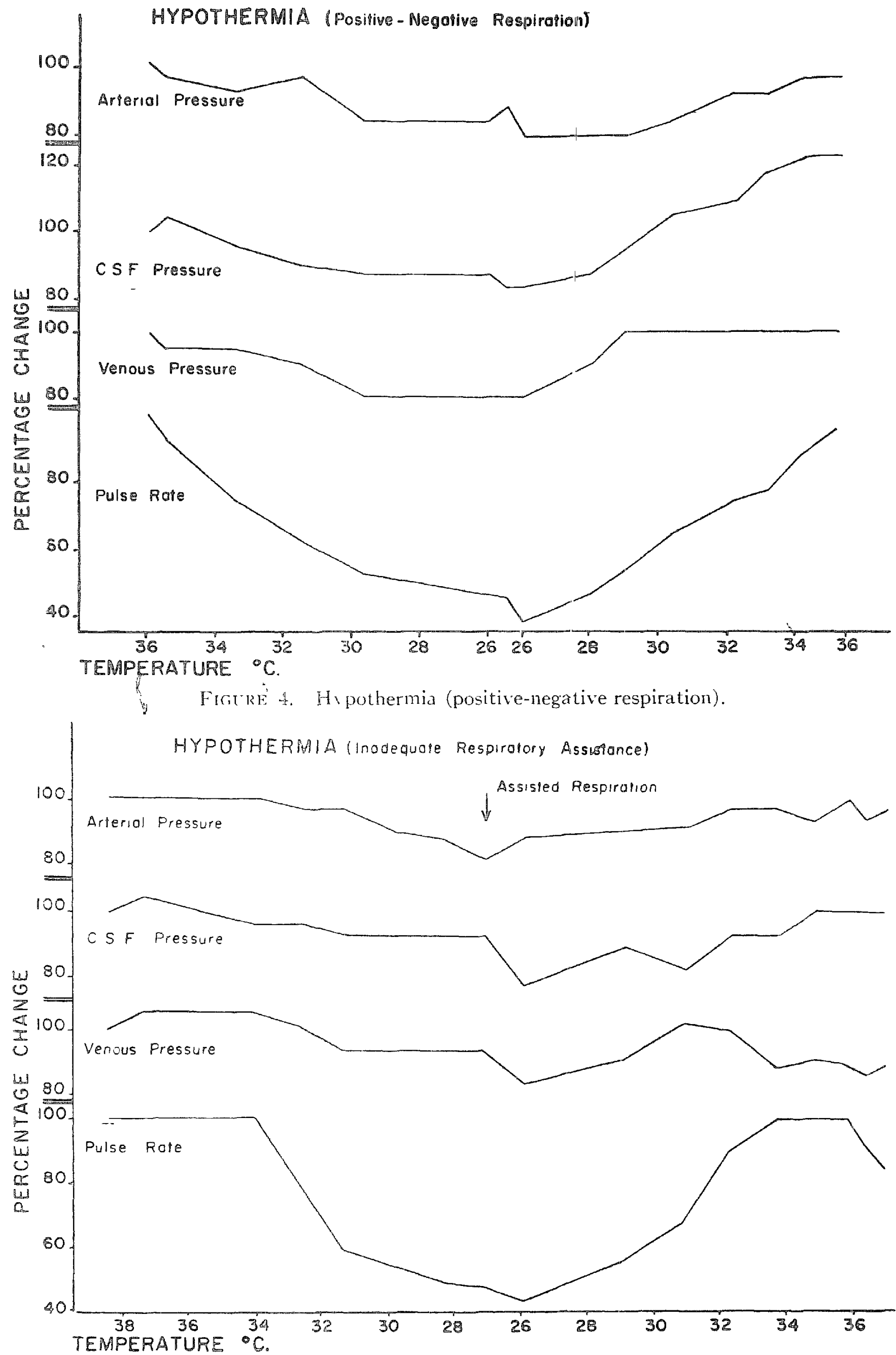

FIGURE 5. Hy pothermia (inadequate respiratory assistance). 


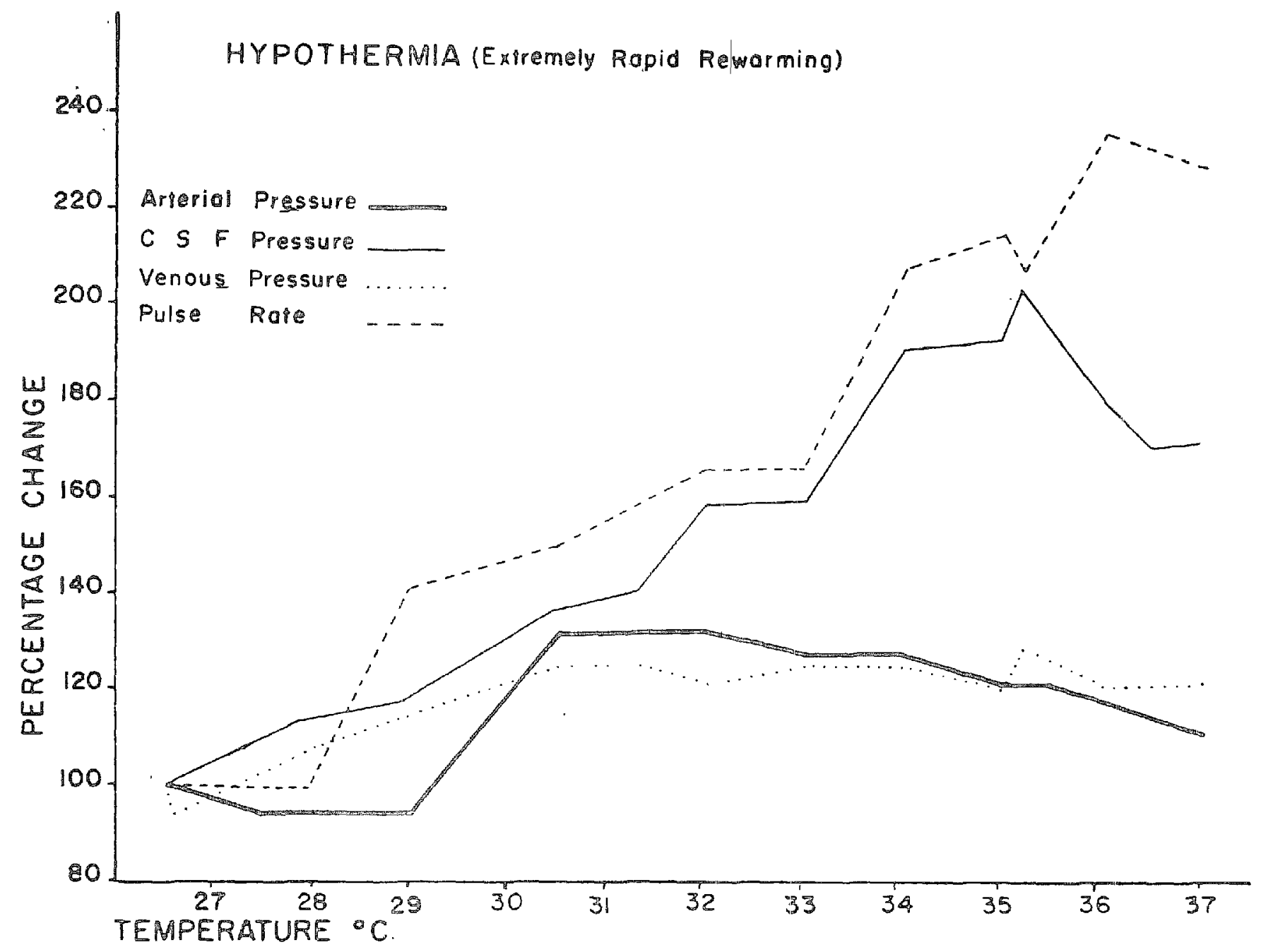

Figure 6. Hypothermia (extremely rapid rewarming).

Figure 6 is an example of a "shocklike" state that occurs with too rapid rewarming (11). There was a fairly close correlation between arterial pressure and venous pressure in this case. A rise in cerebrospinal fluid pressure occurred in spite of the declining arterial and venous pressures. In this particular instance of rewarming there was some relationship between pulse and cerebrospinal fluid pressures.

Perusal of the results obtained in the total group of hypothermia experiments demonstrated no simple relationship between cerebrospinal fluid pressure and pulse rate in either the cooling or the warming phases. Nor was it possible to obtain, under "basal" conditions during cooling, the almost identical relationships Rosomoff illustrated between venous and cerebrospinal fluid pressure (2). During straining, inadequate respiration, and with mechanical positive-negative respiration, however, there was a closer relationship between venous and cerebrospinal fluid pressures. Under these circumstances there was only minimal or moderate reduction of blood pressure and the decrease in cerebrospinal fluid and venous pressures was never marked. The greatest reduction of cerebrospinal fluid pressure occurred only when there was a substantial reduction in arterial pressure. At the lowest temperatures, the percentage reduction of venous pressure tended to approximate that of arterial pressure. When venous pressure rose at low temperatures, the increase in cerebrospinal fluid pressure was not as marked as at higher temperatures. 
Although a fairly standardized method of rewarming was employed, each experiment produced some variation in the relationship of cerebrospinal fluid pressure to arterial and venous pressure and pulse rate (Figs. 2, 3,6). One distinctive feature of the rewarming phase, however, was the very prominent dissociation of the cerebrospinal fluid and venous pressures in most instances (Figs. 2-6).

\section{Normothermia}

The questions raised by the normothermic experiments are being investigated further and, will be elaborated upon in a future article. Some of the results, however, appear to be pertinent to the consideration of cerebrospinal fluid pressure during hypothermia in that they provide further illustration of the complex relationship between cerebrospinal fluid pressure and haemodynamic factors.

Figure 7 shows a marked reduction of cerebrospinal fluid pressure with Arfonad ${ }^{\circledR}$ induced arterial hypotension. There was a decrease in venous pressure, but it was not as marked as the reduction in arterial or cerebrospinal fluid pressure. Following excessive Neosynephrine ${ }^{\circledR}$ administration there was a marked increase of both cerebrospinal fluid and venous pressures. Experience with arterial hypotension in neurosurgery has confirmed this potential hazard of Neosynephrine administration.

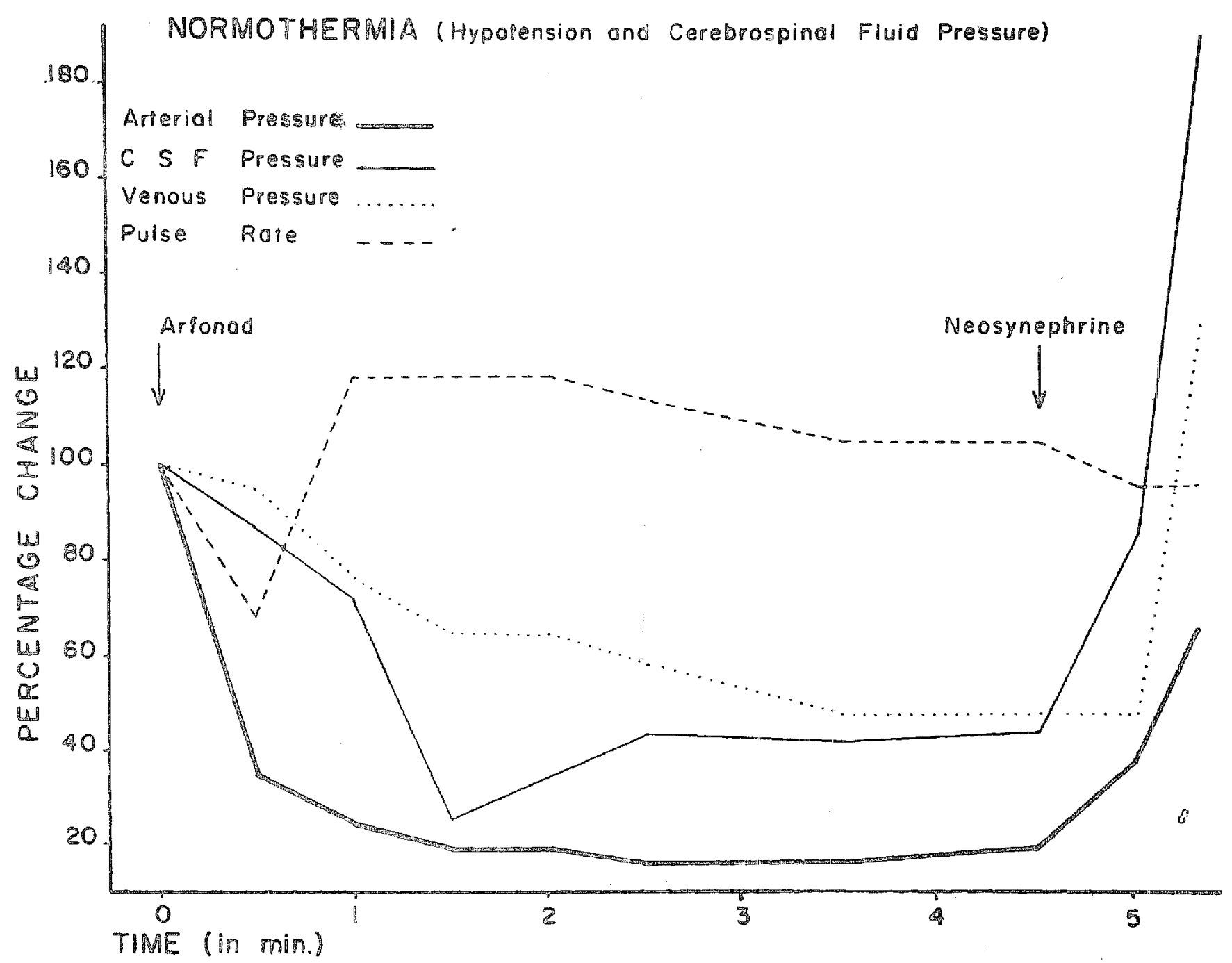

Figure 7. Normothermia (hypotension and cerebrospinal fluid pressure). 


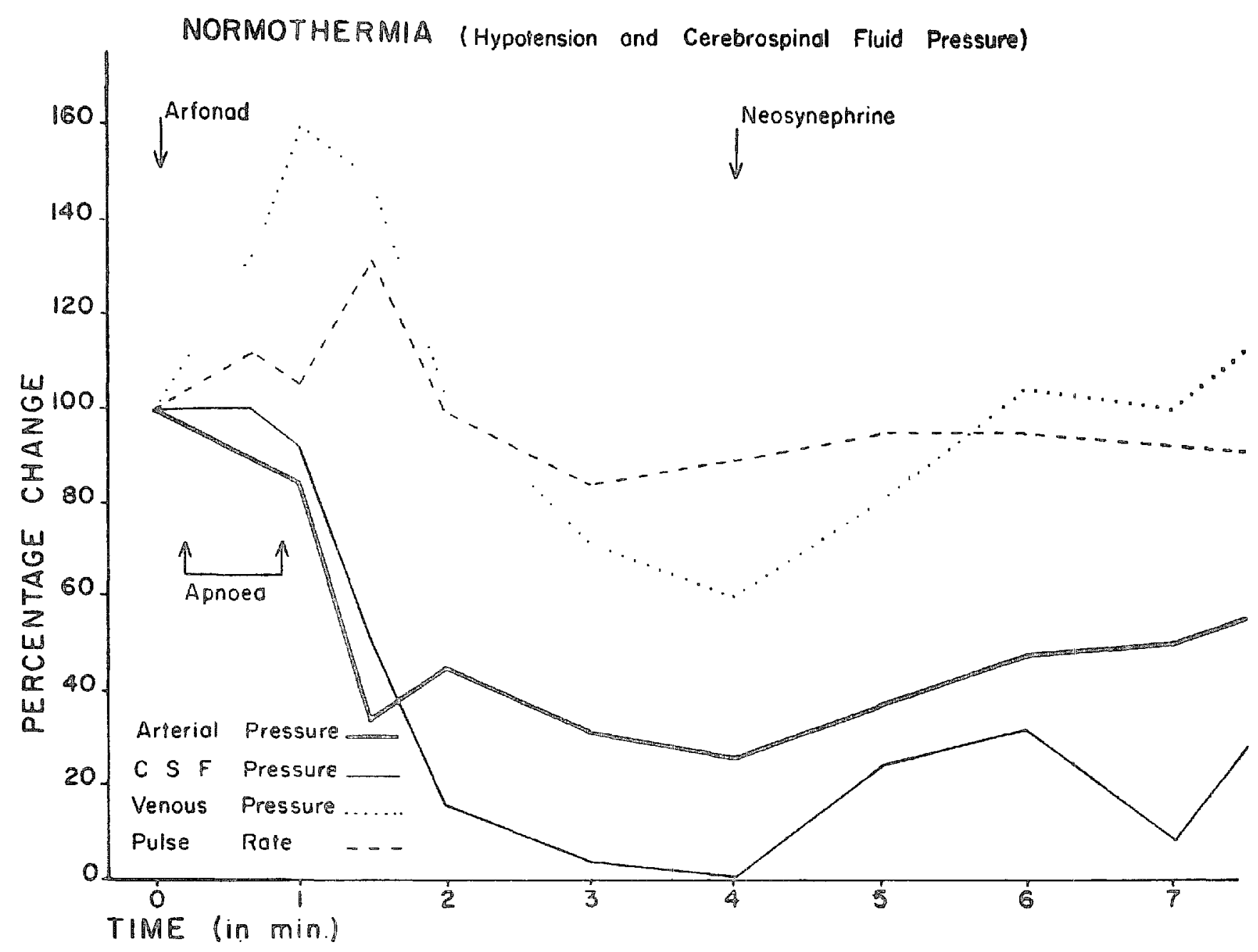

FiguRE 8. Normothermia (hypotension and cerebrospinal fluid pressure).

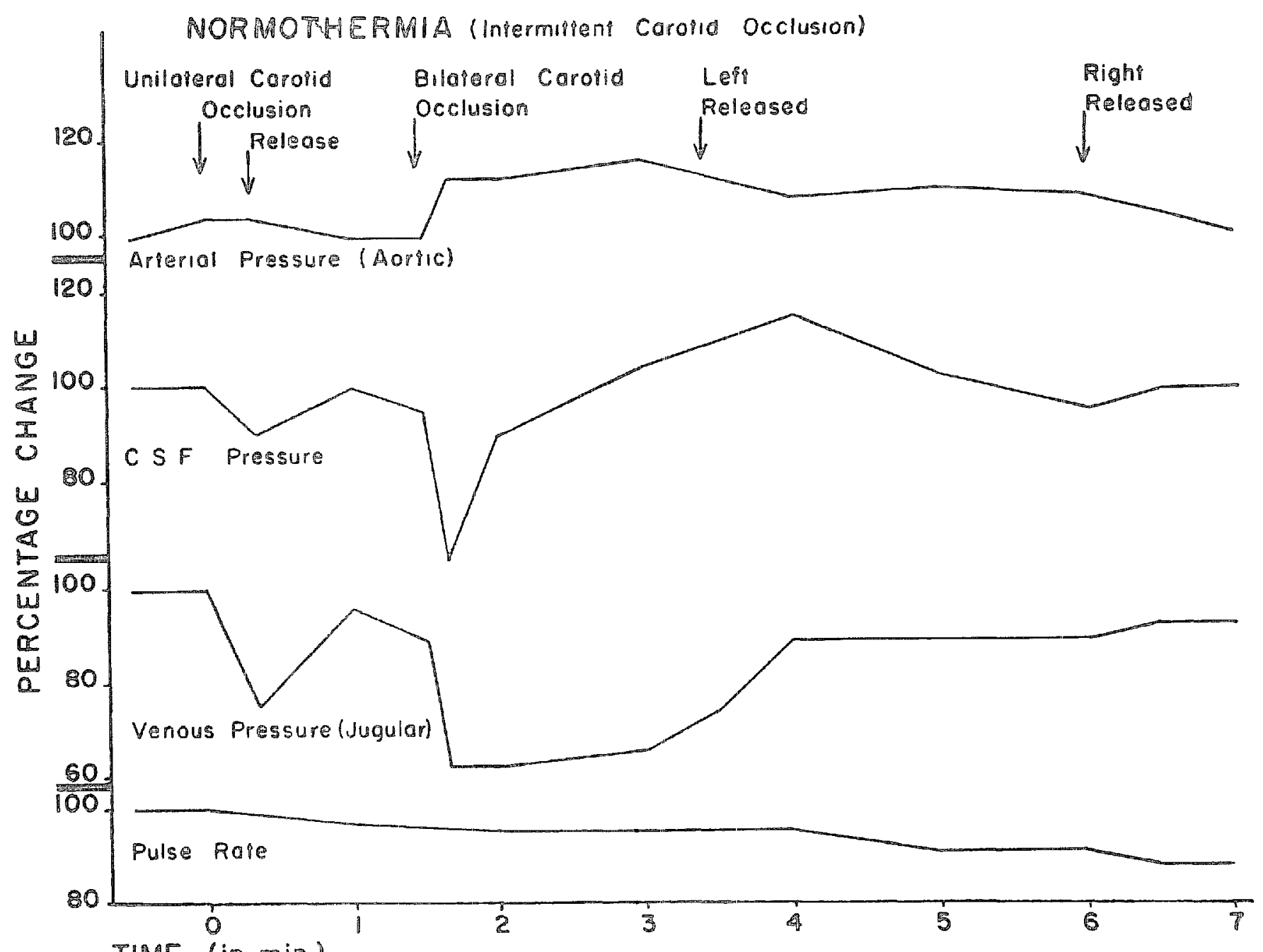

TIME (in min.)

Figler: 9. Normothermia (ihtermittent carotid occlusion). 


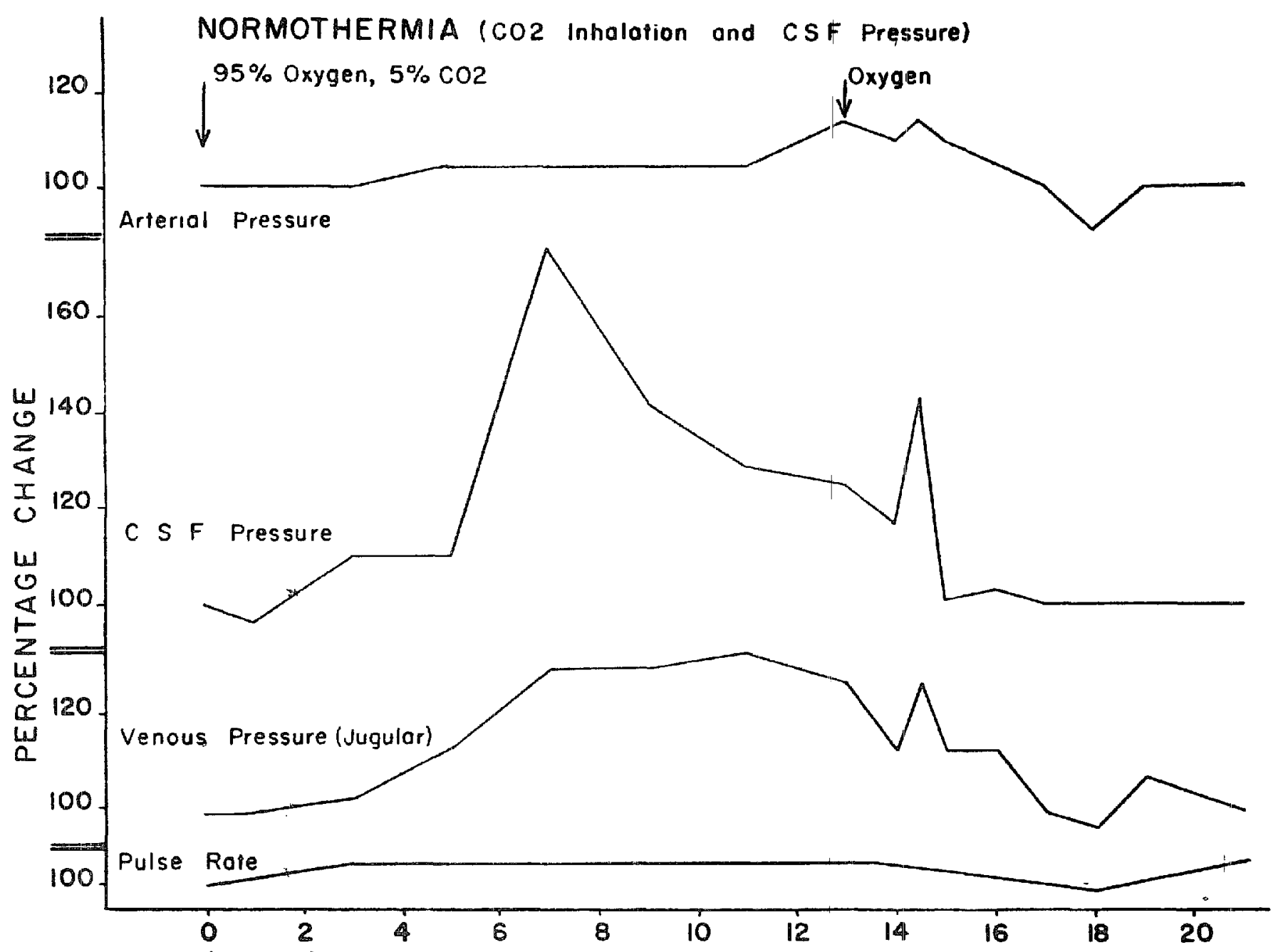

TIME (in $\min$ )

FIgURE 10. Normothermia ( $\mathrm{CO}_{2}$ inhalation and $\mathrm{CSF}$ pressure).

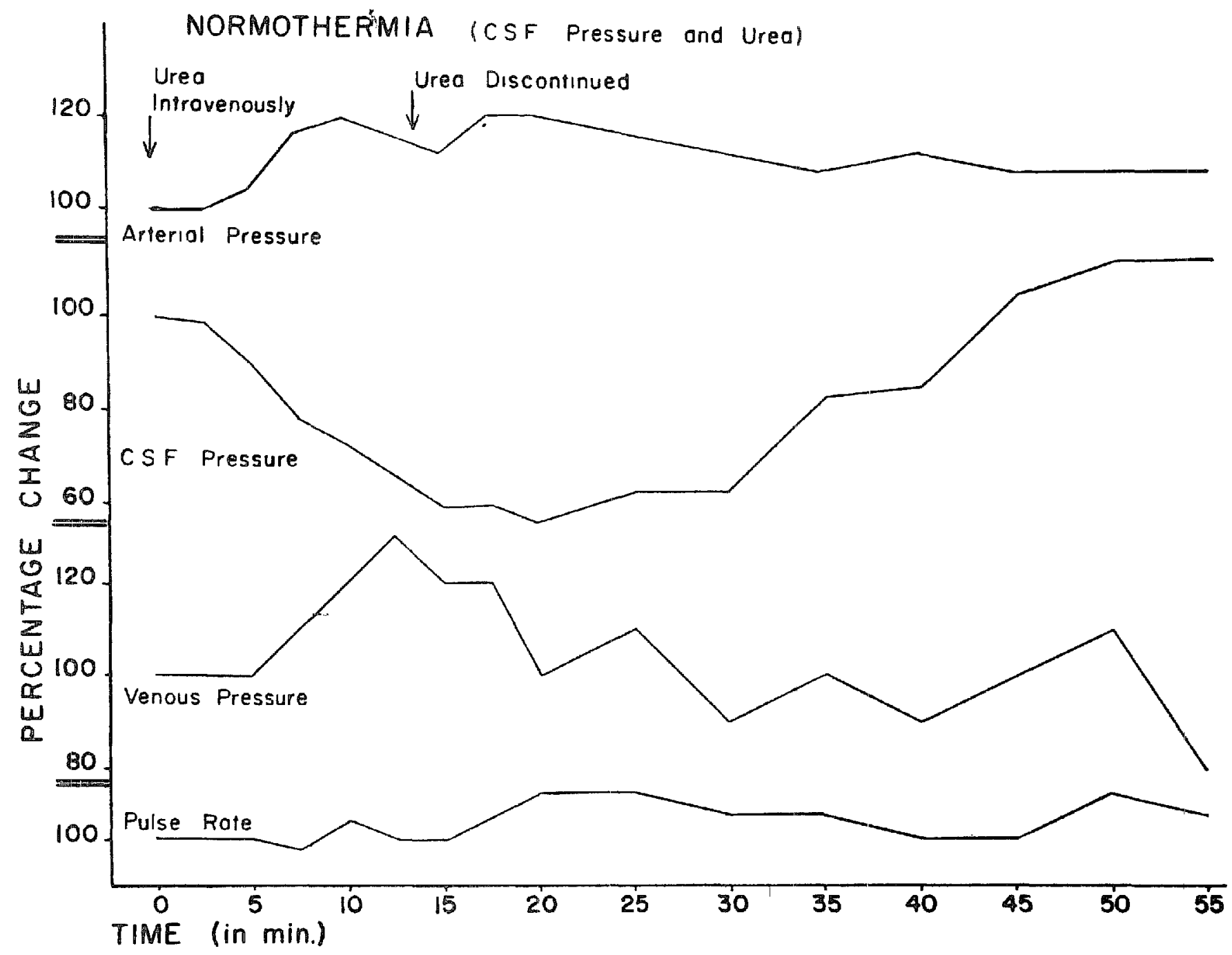

Figure 11. Normothermia (CSF pressure and urea). 


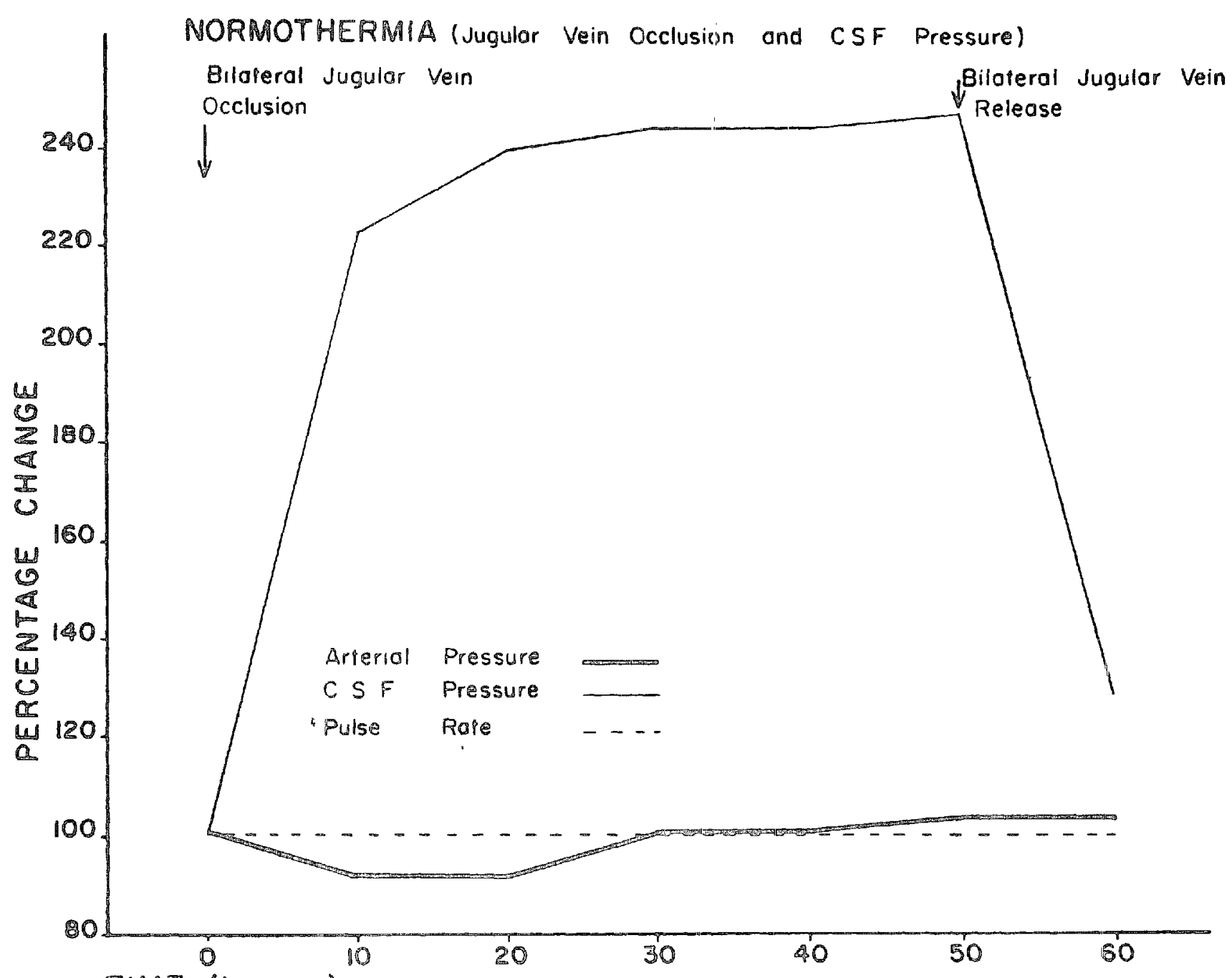

TIME (in Sec)

Figure 12. Normothermia (jugular vein occlusion and CSF pressure).

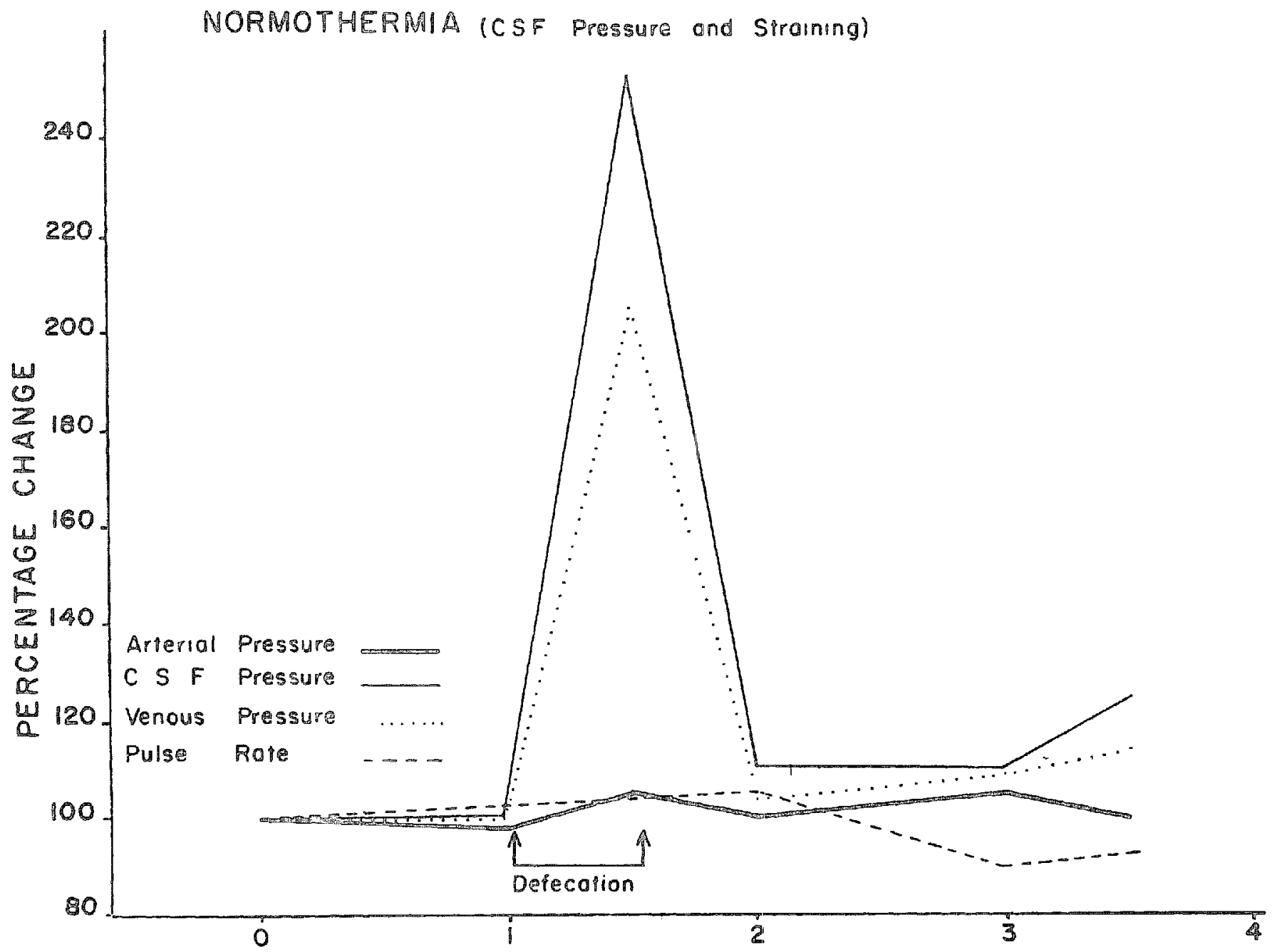

TIME (in min.)

FIGURE 13. Normothermia (CSF pressure and straining). 
Figure 8 illustrates a marked reduction of cerebrospinal fluid pressure following Arfonad administration. This reduction began while venous pressure was still rising during a period of apnoea. Slow administration of Neosynephrine produced a more gradual and less marked venous and cerebrospinal fluid pressure increase than that seen in the preceding example.

Figure 9 illustrates the importance of cerebral blood flow (volume) in the maintenance of cerebrospinal fluid pressure. The fall in cerebrospinal fluid pressure with bilateral carotid occlusion was dramaic.

Figure 10 illustrates the marked rise of cerebrospinal fluid pressure and jugular renous pressure with the administration of 5 per cent carbon dioxide and 95 per cent oxygen, a method known to increase cerebral blood flow by 75 per cent (12). Subsequently, there was a gradual reduction in cerebrospinal fluid pressure without a reduction in jugular venous pressure.

Figure 11 illustrates the marked but transient reduction of cerebrospinal fluid pressure with intravenous urea in spite of a rise of both arterial and venous pressures. The dosage and administration were according to Javid's method (13). Although not illustrated here, intravenous urea, combined with hypothermia, produced an extremely marked and sustained reduction of cerebrospinal fluid pressure.

Figure 12 illustrates the marked rise in cerebrospinal fluid pressure with bilateral jugular venous occlusion. Undoubtedly, this reflects increased intracranial blood volume and the clinical significance is obvious.

Figure 13 illustrates the close relationship between venous pressure and cerebrospinal fluid pressure with straining (defecation) during normothermia.

\section{DISCUSSION}

The initial transient rise of arterial, venous, and cerebrospinal fluid pressures with cooling cannot always be explained by shivering alone (2) as in the "basal" experiments shivering and straining appeared to be completely absent. Lemmon and Davis (14) associated the rise of cerebrospinal fluid pressure with anaesthetic induction and intubation in their clinical hypothermia cases, but this was not applicable to our experiments as cooling was always delayed at least 2 hours following intubation. We have no adequate explanation for this phenomenon.

The complexity of factors influencing cerebrospinal fluid pressure has been illustrated in both normothermia and in hypothermia. During normothermia the close relationship between cerebrospinal fluid pressure and venous pressure during straining was readily demonstrated (Fig. 13). Unlike Rosomoff (2, 15), however, we could not demonstrate the exceedingly close relationship between venous pressure and cerebrospinal fluid pressure reductions during cooling under "basal" conditions. During the rewarming phase the cerebrospinal fluid pressure changes were frequently unrelated to the venous pressure change (Figs. 2-6). Therefore, in addition to venous pressure other haemodynamic factors should be stressed in the reduction of cerebrospinal fluid pressure during cooling and in its rise during rewarming.

Difficult as it is to prove conclusively, it is our impression that during cooling 
the reduction of arterial pressure rather than venous pressure, is the more significant factor in the decrease of cerebrospinal fluid pressure. In addition, venous pressure reduction during codling may be secondary to the arterial pressure decrease. During rewarming no simple and constant relationships were apparent.

During normothermia, however, the significant relationship of arterial pressure to cerebrospinal fluid pressure has been previously demonstrated. Using wide bore needles, $Q^{\prime}$ Connell has shown marked variation, 5 to $50 \mathrm{~mm}$. of water, in cerebrospinal fluid pressure coincident with heart beat, the cerebrospinal fluid pressure rising during systole and falling during diastole (7). Reduction of intracranial pressure during operation has been obtained with hypotension alone (16). We have demonstrated a marked reduction of cerebrospinal fluid pressure with experimental hypotension (Fig. 7) and that this can occur in spite of a marked rise in venous pressure is noteworthy (Fig. 8).

In addition, during normothermia, the profound decrease in cerebrospinal fluid pressure secondary to a diminution of cerebral blood flow has been shown (Fig. 9). By contrast an increase in cerebrospinal fluid pressure was observed coincident with a presumed increase in cerebral blood flow (Fig. 10). Rosomoff has demonstrated the progressive decrease in cerebral blood flow during cooling (17) but did not suggest any direct relationships between cerebral blood flow and cerebrospinal fluid pressure. Measurement of cerebral blood flow during rewarming would be of interest and the role of spinal blood flow as a factor in maintaining cerebrospinal fluid pressure has yet to be determined. Previous workers have emphasized the importance of cerebral blood flow in maintaining cerebrospinal fuid and intracranial pressure during normothermia $(18,19)$.

Finally, the possible factor of osmolarity must also be introduced in the consideration of cerebrospinal fluid pressure. With intravenous urea, both in normothermia and in hypothermia, there was a pronounced cerebrospinal fluid pressure reduction in spite of a rise in arterial and venous pressures (Fig. 11). During hypothermia there is a change in concentration of intravascular contents, but osmotic changes have not been precisely determined $(20,21)$. The possible role of osmolarity in the reduction of cerebrospinal fluid pressure during cooling warrants further investigation.

\section{Conclusions}

1. During cooling there are characteristic patterns of reduction of pulse rate and arterial, venous and cerebrospinal fluid pressures. Under conditions of adequate respiration and absence of straining or shivering, cerebrospinal fluid pressure reduction does not show a simple direct relationship to any of these factors. During rewarming, patterns of correlation are even less apparent.

2. Under certain circumstances of cooling such as straining, shivering and inadequate respiration, there is a close relationship between cerebrospinal fluid pressure and venous pressure.

3. A substantial reduction of cerebrospinal fluid pressure during cooling only occurs when there is an adequate reduction of arterial and venous pressures. Arterial pressure is probably the more significant factor. 
4. During normothermia there is an important relationship between arterial pressure and cerebrospinal fluid pressure. Under certain circumstances there is also an important relationship between cerebrospinal fluid pressure and venous pressure, carotid blood flow and osmolarity.

5. The relationship of cerebrospinal fluid pressure to haemodynamic factors both in normothermia and in hypothermia, remains complex.

\section{ACKNOWLEDGMENTS}

We are deeply indebted to Mrs. M. Weishoff for her most able assistance in the laboratory and to Mr. R. Schneider and Mr. M. Wice for their technical aid in the recording of this data.

\section{RÉSUMÉ}

Antérieurement on a affirmé qu'il existait une relation très étroite entre la diminution de la pression veineuse et la diminution de la pression du liquide céphalo-rachidien au cours du refroidissement, cependant nous n'avons pas réussi à établir l'existence d'une relation aussi étroite si la respiration est maintenue adéquate en évitant tout effort ou tout frisson. La tension artérielle, le pouls et la pression veineuse ont montré des tracés caractéristiques d'abaissement all cours du refroidissement, mais nous n'avons pas observé de corrélation exacte avec la diminution de pression du liquide céphalo-rachidien. Sur les tracés, les signes de corrélation étaient encore bien moins apparents au cours du réchauffement.

Toutefois, lorsque le refroidissement s'accompagnait d'efforts, de frissons ou d'une respiration inadéquate, nous avons observé une relation plus étroite entre les changements de la pression veineuse et ceux de la pression du liquide céphalorachidien. En ces circonstances, nous n'avons pas observé de diminution marquée de la pression du liquide céphalo-rachidien, de la pression veineuse, ni de la pression artérielle et, de plus, le rythme du pouls n'a pas diminué de façon progressive constante.

En général, on a noté une diminution importante de la pression du liquide céphalo-rachidien au cours du refroidissement seulement lorsqu'il existait une diminution adéquate de la pression artérielle et de la pression veineuse. Nous avons l'impression que, au cours de l'hypothermie, si la respiration est adéquate et en l'absence d'effort et de frisson, la diminution de la pression artérielle était probablement le facteur le plus indicateur de cette diminution de pression du liquide céphalo-rachidien.

En certaines circonstances de température normale, des relations entre las pression du liquide céphalo-rachidien, la pression artérielle, le débit sanguin cérébral et l'osmolarité (urée par voie intraveineuse) ont pu s'établir.

De toute façon, soit en présence de température normale, soit au cours de l'hypothermie, il semble complexe d'étalir des relations entre la pression du liquide cephalo-rachidien et les facteurs régissant l'hémodynamique. 


\section{REFERENCES}

1. Bailey, $P$ Intracranial Tumors. 2nd ed. Springfield, Ill.: Charles C. Thomas (1947).

2. Rosomoff, H. L., \& Gilbert, R. Brain Volume and Cerebrospinal Fluid Pressure during Hypothermia. Am. J. Physiol. 183: 19 (1955).

3. Botterell, E. H.; Lougheed, W. M.; Scorr, J. W.; \& Vandewater, S. L. Hypothermia and Interruption of Carotid or Carotid and Vertebral Circulation in the Surgical Management of Intracranial Aneurysms. J. Neurosurg. 13:1 (1956).

4. Howell, D. A., Stratford, J. G., and Posnikoff, J. Prolonged Hypothermia in the Treatment of Massive Cerebral Hemorrhage. Canad. M.A.J. 75:388 (1956).

5. Vandewater, S. L.; Lougheed, W. M.; Scott, J. W.; \& Botterell, E. H. Some Observations with the Use of Hypothermia in Neurosurgery. Anesth. \& Analg. Current Res. 37: 29 (1958).

6. Cushing, H. A Definite Regulatory Mechanism of the Vaso-motor Centre which Controls Blood Pressure during Cerebral Compression. John Hopkins Hospital Bulletin 12: 291 (1901).

7. O'Connell, J. E. A. Vascular Factor in Intracranial Pressure and Maintenance of Cerebrospinal Fluid Circulation. Brain 66: 204 (1943).

8. Posnikoff, J. Electrolyte and Acid-Base Changes in Experimental Hypothermia with Reference to Respiratory Variations. To be published.

9. Hook, W. E, \& Stormont, R. T. Elfect of Lowered Body Temperature on Heart Rate, Blood Pressure and Electrocardiogram. Am. J. Physiol. 133: 134 (1941).

10. Hegnauer, A. H., Shriber, W. J., \& Haterlus, H. O. Cardiovascular Response of the Dog to Immersion Hypothermia. Am. J. Physiol. 161: 455 (1950).

11. Hermbecker, R. O. The Physiology of Induced Hypothermia (Sympesium). Publication 451. National Academy of Sciences, Nat. Res. Council, Washington, D.C., p. 161 (1956).

12. Kety, S. S., Shenkin, H. A., \& Schmidt, C. F. The Effects of Increased Intracranial pressure on Cerebral Circulatory Functions in Man. J. Clin. Invest. 27: 493 (1948).

13. Javid, M. Urea: New Use of an Old Agent. Surg. Clin. North America 38: 907 (1958).

14. Lemmon, L. J., \& Davis, J. S. Studies of Cerebrospinal Fluid Pressure during Hy pothermia in Intracranial Surgery. Surg Gynec. \& Obst. 106: 555 (1958).

15. Rosomoff, H. L. Protective Effects of Hypothermia against Pathological Processes of the Nervous System. Ann. N.Y. Acad. Sci. 80: (2), 475 (1959).

16. Valentine, D. B., Ray, B. S., \& Artusio, J. F., JR. Induced Hypotension as an Aid to Intracranial Surgery. J.A.M.A. 161: 1240 (1956).

17. Rosomoff, H. L., \& Haladay, D. A. Cerebral Blood Flow and Cerebral Oxygen Consumption during Hypothermia. Am. J. Physiol. 179: 84 (1954).

18. Shenkin, H. A. Circulation in Post-operalive Hypotension. J. Neurosurg. 10: 48 (1953).

19. Ryder, H. W.; Espey, F. F.; Kristoff, F. V.; \& Evans, J. P. Observations on the Interrelationships of Intracranial Pressure and Cerebral Blood Flow. J. Neurosurg. 8: 46 (1951).

20. Rodbard, S.; Saiki, H.; Malin, A.; \& Young, C. Significance of Changes in Plasma and Extracellular Volumes in Induced Hypothermia and Hyperthermia. Am. J. Physiol. 16r: 485 (1951).

21. D'Amato, H. E., \& Hegnauer, A. H. Blood Volume in the Hypothermic Dog. Am. J. Physiol. 179: 100 (1953). 